\title{
La revista en tiempos de pandemia. Más tuya que nunca
}

\author{
Estimado lector,
}

Nuestra Revista Uruguaya de Cardiología (RUC) se difunde exclusivamente en formato digital a partir de su volumen 35 (marzo de 2020), en una apuesta que se ha visto catalizada por la terrible pandemia COVID-19. Desde aquel momento, que marcó un hito, el tiraje en formato digital se ha convertido en una oportunidad de avance sustancial, expandiendo el abanico de ámbitos científicos en que se comunican y discuten sus contenidos, a la vez que se gana terreno para ingresar a bases de datos y repositorios de publicaciones más prestigiosas y de mayor impacto. Como vocera de la Sociedad Uruguaya de Cardiología, la RUC es protagonista en construir y consolidar una nueva identidad y prestigio institucional a través de internet y las redes sociales, dejando atrás el formato impreso disponible en el consultorio, la biblioteca o el escritorio de sus socios. De esta manera, la revista se va transformando en un vocero más amplio y potente que aquel de mero "difusor de artículos" que ocupó tradicionalmente. Todo esto requiere articular el trabajo de diversas áreas y perfiles profesionales, actuando codo a codo con el personal de gestión, edición y diseño ya establecido. En este sentido, se inicia la migración progresiva de la gestión editorial aplicando la plataforma digital OJS, en el entendido de que esta modalidad catalizará y optimizará todo el proceso. Los pasos que se vayan dando en este camino serán comunicados en tiempo y forma a lectores, autores, revisores y socios. Pero este desafío sólo puede afrontarse gracias a la excepcional tarea desarrollada por los anteriores editores en jefe, Dres. Gerardo Soca y Victoria Ramos, con el apoyo continuo de Dra. Pilar Aguilar. Está en el horizonte de quien suscribe mantenerlo, potenciarlo y expandirlo, sumando más recursos especializados y aprovechando al máximo los logros alcanzados.

Seguiremos llegando al lector por vía digital en forma continua y regular; una modalidad ensayada e instaurada con éxito en 2020. Así, reiniciamos la entrega de los números del volumen 36, difundiendo una combinación de artículos seleccionados en cada envío, a través del mailing institucional y las redes sociales, en los formatos de cartas científicas, investigaciones originales (completas o abreviadas), revisiones, controversias y editoriales, incluyendo colaboraciones SUC-SEC y comentarios a recomendaciones internacionales o investigaciones de calidad e impacto clínico sustancial. Y proyectamos incluir nuevas secciones para expandir los conocimientos y estimular el debate científico sobre temas estadísticos aplicados, ciencias básicas, educación en cardiología, humanismo y ética.

La pandemia COVID-19 ha impuesto, entre otras cosas, un escenario clínico y asistencial totalmente nuevo, más desafiante, complejo y exigente que nunca. En este momento tan difícil, el personal de la Revista quiere brindar, a su manera, un aliento y estímulo continuo a todos los profesionales de la Salud que atienden las enfermedades del sistema cardiovascular, cuidando de sus pacientes en diferentes niveles de atención, en los subsectores público y privado, en unidades de alta complejidad, el consultorio o el domicilio. Más que nunca, ante el apremio, queremos que te apoderes de la Revista. Con tu lectura, opinión fundada, análisis crítico y participación en la discusión de los contenidos, estarás enriqueciendo la comunidad cardiológica, en lo nacional y extramuros.

Seguí sumándote al desafío. La RUC es tuya. 